\title{
Cold Smoke: smoke-induced density currents cause unexpected smoke transport near large wildfires
}

\author{
N. P. Lareau and C. B. Clements \\ Fire Weather Research Laboratory, San José State University, San José, CA, USA \\ Correspondence to: N. P. Lareau (neil.lareau@sjsu.edu)
}

Received: 13 April 2015 - Published in Atmos. Chem. Phys. Discuss.: 2 July 2015

Revised: 18 September 2015 - Accepted: 23 September 2015 - Published: 20 October 2015

\begin{abstract}
The first observations of smoke-induced density currents originating from large wildfires are presented. Using a novel mobile Doppler lidar and additional in situ measurements, we document a deep $(\sim 2 \mathrm{~km})$ smoke-filled density current that propagates more than $25 \mathrm{~km}$ at speeds up to $4.5 \mathrm{~m} \mathrm{~s}^{-1}$ near a large forest fire in northern California. Based on these observations we show that the dynamics governing the spread of the smoke layer result from differential solar heating between the smoke-filled and smoke-free portions of the atmospheric boundary layer. A calculation of the theoretical density current speed agrees well with the observed propagation speed. Additional lidar and photographic documentation of other smoke-filled density currents demonstrate that these previously unknown phenomena are relatively common near large wildfires and can cause severe and unexpected smoke inundation of populated areas.
\end{abstract}

\section{Introduction}

Smoke from forest fires adversely affects human health (Johnston et al., 2012), reduces visibility, and alters the earth's radiative energy balance (Penner et al., 1992). The multi-scale atmospheric dynamics affecting smoke dispersion cause these smoke impacts to occur both close to, and far from, large wildfires. For example, when smoke becomes trapped in mountain valleys it can recirculate for many days (Robock, 1988, 1991), whereas when injected aloft it can cause downwind impacts thousands of kilometers away (Pahlow et al., 2005; Fromm et al., 2010). Despite advances in multi-scale smoke transport modeling, forecasts for smoke dispersion continue to suffer from uncertainties in fire emissions, smoke injection depth, and the physics of fire-atmosphere interactions (Larkin et al., 2009; Goodrick et al., 2012). For example, numerical models struggle to predict smoke concentrations during complex synoptic-scale and topographic flow interactions, especially in narrow mountain valleys (Strand et al., 2012). Moreover, many operational forecast models neglect smoke radiative effects, leading to potential errors in smoke dispersion forecasts due to unresolved feedbacks between smoke and atmospheric circulations. These shortcomings are compounded by the lack of observational studies examining the physical processes and feedbacks that contribute to smoke dispersion, especially in complex terrain.

A key component of fire-atmosphere interaction is smoke modification of the earth's radiative energy balance due to the scattering and absorption of solar and terrestrial radiation (Penner et al., 1992; Hobbs et al., 1997). For smoke of sufficient optical depth, the reduction in downwelling shortwave radiation causes a substantive decrease in daytime temperature, suppressed convective boundary layer growth, or even persistent near-surface temperature inversions (Robock et al., 1988; Segal et al., 1989; Garrett et al., 1990). These effects are collectively known as smoke shading. Furthermore, since smoke minimally affects nocturnal infrared cooling, a strong positive feedback between nocturnal inversion duration and suppressed smoke dispersion can contribute to multi-week persistent inversions in mountain valleys (Robock, 1988, 1991). These inversions can subject communities to prolonged exposure to hazardous levels of small particulate matter (e.g., $\mathrm{PM}_{2.5}$ ), which has been linked to a host of deleterious health affects (e.g., Delfino et al., 2009; Wegesser et al., 2009; Holstius et al., 2012).

Smoke shading is also a hypothesized, but heretofore unobserved, mechanism for thermally driven mesoscale circu- 
lations, which can strongly affect smoke dispersion (Segal and Arritt, 1992). These circulations are dynamically similar to sea breezes and develop from spatial gradients in surface sensible heat flux (Segal and Arritt, 1992). The resulting difference in near-surface air temperature induces thermally direct flow, the leading edge of which is often delineated by a mesoscale front. The propagation of these "mesofronts" is well described by density current theory (Simpson and Britter, 1980). Mesoscale circulations of this sort have been observed due to heterogeneous snow cover (Johnson et al., 1984), shading by thunderstorm anvils (Markowski et al., 1997), and gradients in soil moisture and surface albedo (Rife et al., 2002). Their impact on pollution transport, and in this case smoke dispersion, is a topic of considerable interest because their flow characteristics are highly nonlinear and can cause dispersion against the mean wind (Simpson, 1997).

In this paper we present first observations and analyses of smoke-induced density currents, which are previously undocumented processes affecting smoke transport near large wildfires. Using a novel truck-mounted Doppler lidar, radiosonde system, and automatic weather station (Clements and Oliphant, 2014), we show that these density currents form due to differential solar heating between smoke-filled and smoke-free portions of the atmospheric boundary layer and can unexpectedly spread smoke counter to the ambient wind and over large distances $(\sim 30 \mathrm{~km})$. Based on these observations and additional photographic evidence, we propose that smoke-induced density currents are relatively common near wildfires and must be considered for improved smoke dispersion forecasts and managing smoke impacts on communities.

\section{The Bald and Eiler fires}

The primary focus of this study is a smoke-induced density current originating from the Bald and Eiler fires, which burned in close proximity in northern California from 30 July-12 August 2014 (Fig. 1a). Both fires were started by lightning and grew quickly, producing towering convective plumes reaching depths in excess of $9 \mathrm{~km}$. At night, when fire behavior moderated, smoke pooled in nocturnal temperature inversions forming within the broad, flat-bottomed Hat Creek valley (Fig. 1a). For example, on the morning of 3 August, radiosonde and lidar data show thick smoke confined within a $400 \mathrm{~m}, 7 \mathrm{~K}$ surface-based temperature inversion (Fig. 1b). Meanwhile, satellite images indicate that the adjacent Feather Lake plateau remained smoke free throughout the morning (Fig. 1c), allowing for significant differential solar heating between the two locales.

By midday this smoke-induced thermal contrast initiated a propagating density current that rapidly spread the cold, smoke-filled layer to the southeast across the Feather Lake plateau. The approximate sequential positions of the leading edge of the smoke-filled mesofront are traced from vis-
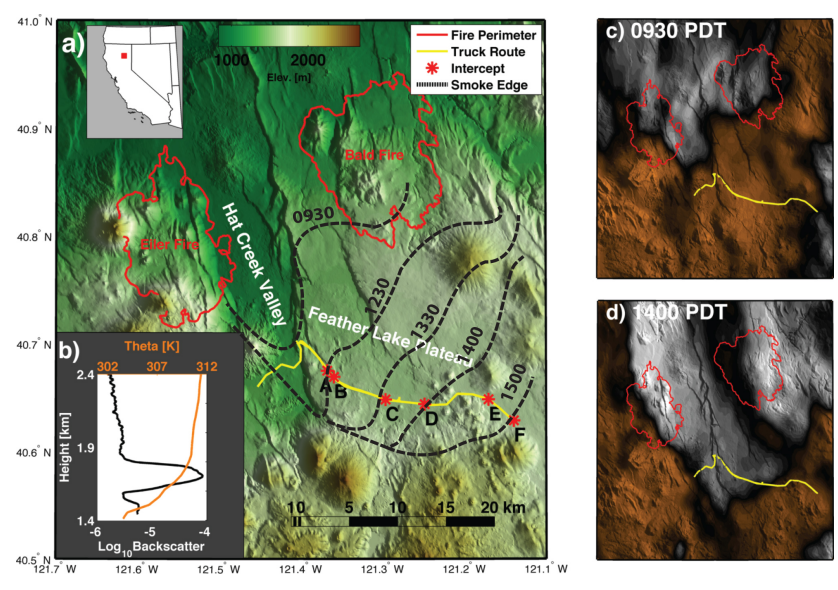

Figure 1. Overview of the smoke-induced density current on $3 \mathrm{Au}-$ gust 2014. (a) Map of the regional topography (shaded and shadowed), the Bald and Eiler fire perimeters (red lines), smoke front isochrones (dashed black lines labeled in PDT), density current intercept locations (lettered red stars), and driving route (yellow line). (b) Vertical profile of potential temperature (orange) and lidar backscatter $\left(\mathrm{m}^{-1} \mathrm{sr}^{-1}\right.$, black) from the Hat Creek valley at 09:00 PDT. (c, d) False color visible satellite images overlaid on the topography and showing the smoke extent at 09:30 and 14:00 PDT, respectively. The colors are adjusted to highlight smoke and clouds (grays) versus smoke-free, cloud-free regions (browns).

ible satellite images and in situ observations (dashed lines, Fig. 1a). Between local noon and 15:00 PDT (Pacific daylight time), the smoke spread more than $25 \mathrm{~km}$, inundating a large area with optically thick smoke (Fig. 1d). Notably, the direction of smoke propagation was counter to the prevailing southerly flow aloft, which was as strong as $12.5 \mathrm{~m} \mathrm{~s}^{-1}$.

\section{Observations of the density current}

During its southeastward excursion across the Feather Lake plateau the leading edge of the smoke-induced density current was intercepted 6 times with the truck-mounted Doppler lidar and instrumentation. The vertically pointed $1.5 \mu \mathrm{m}$ lidar samples at $\sim 1 \mathrm{~Hz}$ using a range gate resolution of $18 \mathrm{~m}$ and a total range of $9.6 \mathrm{~km}$. The lidar backscatter is sensitive to aerosol in the size range of a few microns, e.g. $\mathrm{PM}_{2.5}$, and thus provides high values of backscatter for forest fire smoke. The lidar also samples the line-of-sight velocity at a resolution of $\sim 1 \mathrm{~cm} \mathrm{~s}^{-1}$. A unique aspect of the truck-mounted lidar is the ability to sample in motion, thereby providing spatially and temporally resolved profiles of the atmospheric boundary layer, or in this case the structure of a smoke-filled density current as it moved across the landscape. Further details of the observation platform, including the radiosonde system, are available in Clements and Oliphant (2014).

The density current intercept locations and corresponding lidar backscatter are shown in Figs. 1a, 2, and 3, respectively. Common to each intercept are the canonical features 


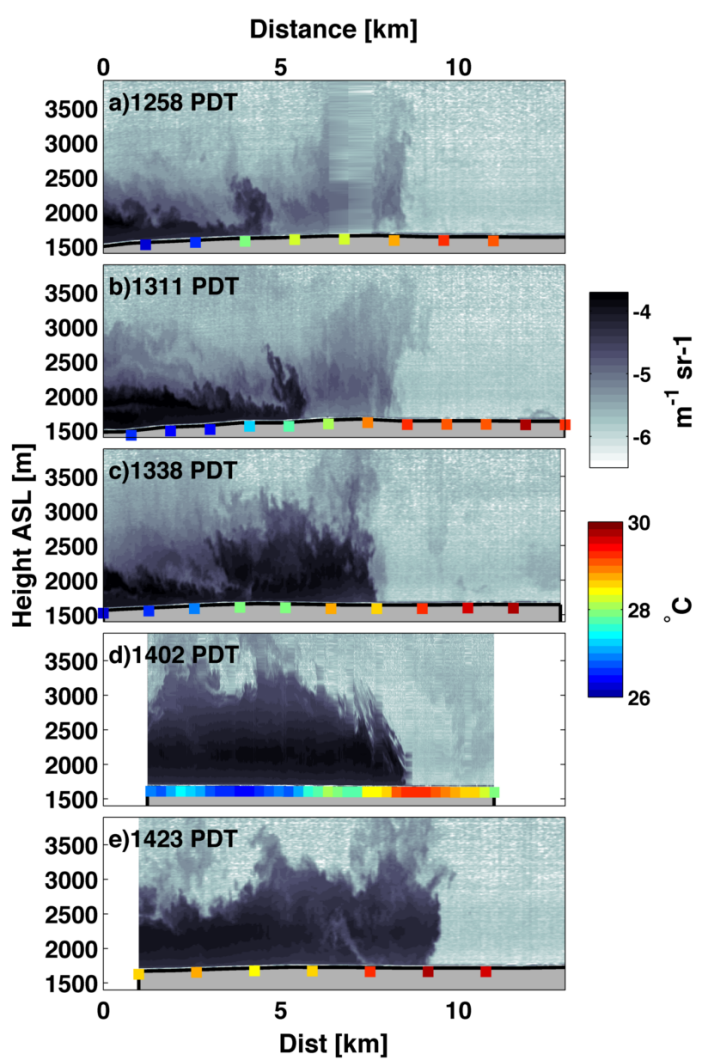

Figure 2. Lidar backscatter (shading, $\mathrm{m}^{-1} \mathrm{sr}^{-1}$ ) and near-surface temperature (colored squares) for density current intercepts A-E. Times, in PDT, correspond to the center of the time range in each panel. The data for intercept $\mathrm{D}$ were recorded while the truck was stationary, but have been mapped to the spatial coordinate using the estimated frontal speed of $4.6 \mathrm{~m} \mathrm{~s}^{-1}$. All distances are relative to an arbitrary point.

of an atmospheric density current including a sharp frontal zone, elevated head, substantive temperature contrast, shallower following flow, and interfacial wave mixing (Britter and Simpson, 1978; Simpson and Britter, 1979, 1980; Simpson, 1997). For example, the near-surface air temperature (colored squares, Fig. 2) substantively decreases across the leading edge of the density current, which is defined by a sharp increase in lidar backscatter where the smoke layer undercuts the smoke-free boundary layer. The backscatter in the clear air is nearly zero due to pristine conditions outside of the fire-modified environment.

The intercept sequence also reveals changes in the density current structure between the onset, maturation, and eventual decay of the circulation. At the onset, the leading edge of the circulation is marked by an isolated smoke-filled updraft followed by shallow near-surface flow (Fig. 2a, b). The density current circulation subsequently deepens as the smoke layer advances to the east-southeast. For example, at intercept $\mathrm{C}$ the head region is observed to broaden and deepen (Fig. 2c) and the Doppler velocity data show increased vertical mix-

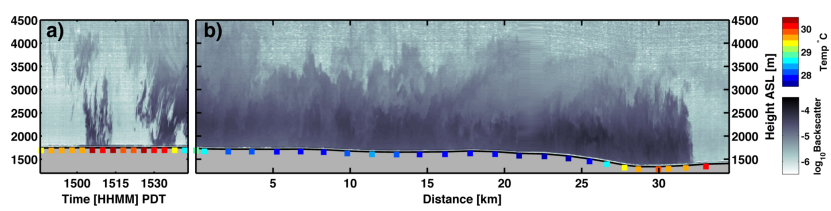

Figure 3. Final intercept and return transect through the smoke layer. (a) Lidar backscatter and truck temperature at intercept $\mathrm{F}$ at 15:00 PDT, which marks the foremost advance of the smoke-filled density current. (b) Lidar backscatter and truck temperature during the return transect from intercept $\mathrm{F}$ to the Hat Creek valley. Panel (a) is plotted against time while the truck was stationary, whereas (b) is plotted against driven distance from intercept $\mathrm{F}$.

ing (not shown). The increased mixing contributes to a more homogenous density current at intercept D (Fig. 2d), where the isolated plume at the leading edge is no longer apparent and the following flow is deeper and better mixed.

Intercepts $\mathrm{E}$ (Fig. 2e) and F (Fig. 3a) reflect the slowing and eventual decay of the density current circulation. For example, at intercept $\mathrm{E}$ the leading edge of the density current develops an elevated nose wherein the foremost smoke is found aloft. Laboratory experiments indicate that the height of the nose depends on the comparative magnitude of the density current speed and surface frictional effects (Britter and Simpson, 1978; Simpson and Britter, 1979). In this case the density current advance is slowing, perhaps due to flowtopography interaction or a decrease in the negative buoyancy. The backscatter at intercept $\mathrm{E}$ also indicates an embedded front within the following flow, suggesting that cleft and lobe instabilities cause portions of the front to laterally fold over on itself (Simpson, 1997; Mayor, 2011).

Finally, intercept F (Fig. 3a) corresponds with the foremost advance of the smoke layer, consistent with the satellite observations and the frontal isochrones in Fig. 1a. At that time the leading edge of the smoke layer was diffuse and ragged as it drifted back and forth across the truck-mounted instrumentation, which was now parked. Following the stagnation of smoke layer the truck was driven back to the Hat Creek valley. The lidar backscatter along the return transect reveals the full extent of the smoke layer blanketing the Plateau (Fig. 3b). Substantial wave activity and a continued multilayered structure are noted and the truck temperature sensor indicates suppressed near-surface temperatures throughout the smoke layer, with the coldest temperatures corresponding to the regions of the highest aerosol backscatter, indicative of smoke shading. The western edge of the smoke layer, and a corresponding increase in near-surface temperature, was subsequently observed within the Hat Creek valley.

\subsection{Density current dynamics}

In this section, the dynamics governing the advance of the smoke-induced density current are examined using additional lidar wind profiles and radiosonde data during the 

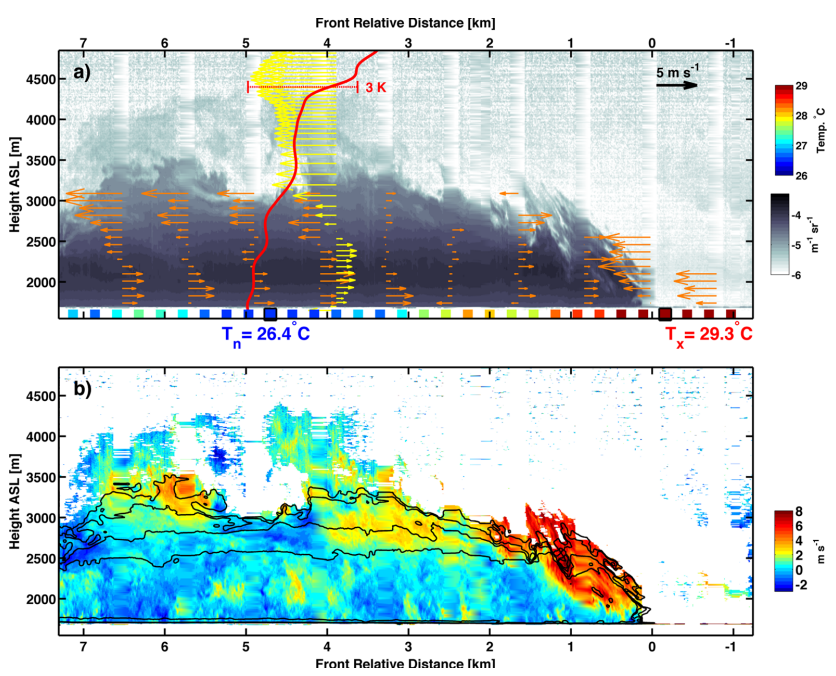

Figure 4. The anatomy of the smoke-induced density current during intercept D at 14:02 PDT. (a) Logarithmic attenuated backscatter $\left(\mathrm{m}^{-1} \mathrm{sr}^{-1}\right)$ overlaid with the lidar derived front-relative horizontal winds (orange), radiosonde front-relative winds (yellow), radiosonde potential temperature (red), and near-surface air temperatures (shaded squares). The maximum $\left(T_{x}\right)$ and minimum $\left(T_{n}\right)$ temperatures are annotated. (b) lidar vertical velocity (shaded) and smoke backscatter (black contours at $-4,-4.5$, and $-5 \mathrm{~m}^{-1} \mathrm{sr}^{-1}$ ).

fourth intercept (Fig. 4). These data were obtained as the density current passed over the truck-mounted instrumentation, which had been parked in advance of the propagating smoke front. The wind profiles were collected every 3 min using a Doppler beam swinging technique (Lane et al., 2013). As we show below, these observations, when compared with laboratory experiments and theory, support our hypothesis that the observed smoke propagation is "self-induced" due to the thermal contrast resulting from smoke shading of the boundary layer.

\subsubsection{Thermal structure}

At the surface, the warmest air $\left(29.3^{\circ} \mathrm{C}\right)$ immediately precedes the leading edge of the density current while the coldest air $\left(26.4^{\circ} \mathrm{C}\right)$ follows about $4 \mathrm{~km}(\sim 17 \mathrm{~min})$ behind (colored squares, Fig. 4a). From the equation of state, we compute that the observed temperature difference is equivalent to a $\sim 1 \%$ increase in air density within the cold smokefilled layer. The source of the temperature contrast is the differential solar heating between the smoke-free Feather Lake plateau and the smoke-filled nocturnal inversion in the Hat Creek valley. Similar cross-front temperature (i.e., density) gradients were observed during the first four intercepts, but decreased thereafter as the density current slowed and then came to rest.

Above the surface, the density current potential temperature profile exhibits a multi-layered stably stratified structure (red line, Fig. 4a). The lowest $850 \mathrm{~m}$ of the flow is com- posed of cold, undiluted, smoke-filled air emanating from the Hat Creek valley. The mean potential temperature deficit is $\sim 2 \mathrm{~K}$, indicating that the layer averaged density contrast is somewhat less than that determined from the surface temperatures alone. This result suggests that a shallow superadiabatic layer preceding the arrival of the density current influences the near-surface temperature gradient.

The second layer, which is $\sim 500 \mathrm{~m}$ deep, is linearly stratified and contains intermediate smoke concentrations. The linear stratification and diluted smoke are due to wavegenerated mixing of the scalar properties of the lowest layer with the warmer, smoke-free air ahead of the advancing front. This wave-driven entrainment is visually apparent in the backscatter data during each of the intercepts and contributes to increasing smoke depth throughout the evolution of the density current.

The layer above the density current comprises smoke-free, neutrally stratified, and potentially warmer air in the ambient convective boundary layer. The density current undercuts this layer as it spreads to the southeast. As is typical, the convective boundary layer is capped by a temperature inversion, which in this case acts as a semi-rigid lid on the system, making our environmental observations comparable to idealized laboratory experiments of density currents propagating into neutrally stratified environments (Simpson and Britter, 1980).

\subsubsection{Kinematic structure}

The multi-layered structure of the density current is also observed in the front-relative wind (vectors, Fig. 4a), which is computed by subtracting the mean motion of the front from the wind profiles. In the front-relative reference frame, the lowest layer (i.e., the undiluted core) exhibits a coherent overtaking flow that exceeds the speed of the front. The ratio of the overtaking speed to the front speed is $\sim 1.3$, reflecting a $6 \mathrm{~m} \mathrm{~s}^{-1}$ flow from $305^{\circ}$, representative of the mean motion of the smoke front across the plateau.

An opposing front-relative wind of $\sim 6 \mathrm{~m} \mathrm{~s}^{-1}$ is observed ahead of and above the density current. In absolute terms, the near-surface flow is $\sim 2 \mathrm{~m} \mathrm{~s}^{-1}$ from the southeast whereas the flow aloft is $\sim 12.5 \mathrm{~m} \mathrm{~s}^{-1}$ from the south. As such, it is clear that the smoke layer moves in opposition to the ambient wind near the surface and at an approximately right angle to the flow aloft. This motion constitutes an unexpected spread of the smoke, which is typically assumed to advect with the ambient wind.

The adjustment between the ambient flow in the undisturbed convective boundary layer and the flow within the density current occurs within the intermediary layer, which exhibits a sharply sheared wind profile and is dominated by front-relative rearward flow. This flow sweeps diluted smoke generated from wave-driven entrainment towards the northwest and contributes to the deepening of the density current overtime. 
The entrainment and mixing is most substantial in the density current head. There, the strong convergence between the overtaking flow and the opposing flow produces a $1 \mathrm{~km}$ long, $2 \mathrm{~km}$ deep, rearward sloping updraft (Fig. 4b). The maximum vertical velocity is $8 \mathrm{~m} \mathrm{~s}^{-1}$, significantly exceeding typical vertical velocities in the convective boundary layer and reflecting a major pathway for vertical mixing of smoke.

\subsubsection{Speed of the front}

The speed of the front is initially estimated from the location and timing of adjacent smoke front intercepts with the truck-mounted instruments (Fig. 1a). For example, using geometric considerations we determine that the front moved at an average speed of $\sim 4.6 \mathrm{~m} \mathrm{~s}^{-1}$ between intercepts $C$ and $D$, but then slowed substantially as it passed through intercept $\mathrm{E}$, and eventually came to rest at intercept F, which marks the foremost extend of the smoke layer near 15:00 PDT (Fig. 1a).

To test the hypothesis that the observed spread of the smoke layer results from the differential heating across the smoke front, we compare the observed front speed at intercept D with the theoretical density current speed (Simpson and Britter, 1980; Mayor, 2011) given by

$V_{\text {front }}=C \sqrt{\left(\frac{\theta_{\mathrm{s}}-\theta_{\mathrm{a}}}{\theta_{\mathrm{a}}}\right) g H_{4}}-.62 V_{\text {wind }}$.

In Eq. (1) $C$ is the internal Froude number $(0.82), \theta_{\mathrm{S}}$ is the mean potential temperature of the undiluted smoke layer $(\sim 314 \mathrm{~K}), \theta_{\mathrm{a}}$ is the ambient potential temperature $(\sim 316 \mathrm{~K})$, $g$ is gravity, $H_{4}$ is the depth of the undiluted layer $(850 \mathrm{~m})$, and $V_{\text {wind }}$ is the ambient wind component opposing the frontal motion near the surface $\left(2 \mathrm{~m} \mathrm{~s}^{-1}\right)$. With these values, the computed frontal speed is $4.7 \mathrm{~m} \mathrm{~s}^{-1}$, which closely matches the estimated speed determined from the frontal displacement.

This important result demonstrates that the propagation of the smoke layer is attributable to the thermal contrast resulting from smoke shading and confirms the hypothesis of Segal and Arritt (1992) that thick smoke can induce "non-classical" mesoscale circulations. As a corollary, we also conclude that unlike sediment-driven density currents in other geophysical flows (turbidity currents, powder avalanches, etc.) (Simpson, 1997), the increase in density due to the mass of suspended smoke is minimally important to this circulation. This conclusion is reinforced by considering the contributions to the negative buoyancy $(B)$ of an air parcel, which, following Markowski and Richardson (2011), is given by

$B \approx\left[\left(\frac{\theta_{\mathrm{s}}-\theta_{\mathrm{a}}}{\theta_{\mathrm{a}}}\right)+\left(\frac{R}{C_{\mathrm{p}}}-1\right) \frac{P^{\prime}}{\bar{P}}-r_{\mathrm{s}}\right] g$,

where the first term in the brackets is the thermal anomaly as in Eq. (1), the second term is the pressure perturbation, and the third term is the mixing ratio of suspended particulates, in this case smoke $\left(r_{\mathrm{s}}\right)$. From Eq. (2) it can be shown that smoke loading of $\sim 10 \mathrm{~g} \mathrm{~kg}^{-1}$ is necessary to produce a density perturbation comparable to the observed thermally induced negative buoyancy (e.g., $\sim-3 \mathrm{~K} / 300 \mathrm{~K}$ ). Since, smoke concentrations are unlikely to significantly exceed $1000 \mu \mathrm{g} \mathrm{kg}^{-1}$ outside of vigorous fire-generated updrafts (http://www.arb. ca.gov/smp/progdev/pubeduc/smphfs0702.pdf; Trentmen et al., 2006), the suspended smoke is likely only important for its radiative effects and not its direct contribution to negative buoyancy.

\section{Discussion}

In this section we present additional observations of smokeinduced density currents near large wildfires. These data indicate that smoke-induced density currents are a surprisingly common feature of large multi-day forest fires. We also discuss the interaction of these density currents with other thermally driven flows in complex terrain.

Figure 5 presents additional mobile lidar backscatter and truck air temperature observations obtained adjacent to the Eiler fire on 2 August, the day before the density current examined in Sect. 3. These data show a north-south propagating smoke-filled layer accompanied by a $2 \mathrm{~K}$ thermal contrast between the smoke-free and smoke-filled portions of the boundary layer. Compared to the observations in Sect. 3, this smoke-layer possesses fewer distinct density current characteristics and propagates over a more limited geographic extent. Nevertheless these data provide additional evidence for smoke shading as a mechanism to produce substantive horizontal gradients in the near-surface temperature capable of driving mesoscale circulations that affect smoke transport.

Further, it is interesting to note that the density current timing on both 2 and 3 August is similar (e.g., near noon), and we speculate that these density currents may superimpose on thermally driven flow reversals from down valley to up valley winds. While we lack sufficient observations preceding the Bald and Eiler fires to assess how smoke alters the strength and timing of these terrain-driven flows, it stands to reason that the up valley afternoon flow will be enhanced due to the differential smoke shading superimposed on the typical along valley and along slope temperature gradients. In this sense, the smoke-filled density current may behave similarly to sea-breeze circulations embedded in upslope flows in coastal topography, a superposition which is known to produce a stronger circulation than either process acting independently (Mahrer and Peilke, 1977).

Additional evidence for the propensity for smoke-induced density currents and the interaction of density currents with diurnal mountain wind systems is presented in Fig. 6, which shows a sequence of photographs extracted from a time lapse of a smoke-filled density current on 20 September 2014. In this instance the smoke layer spread more than $30 \mathrm{~km}$ from its source (the King fire; http://inciweb.nwcg.gov/incident/ 4108/), crossed the crest of California's Sierra Nevada, 


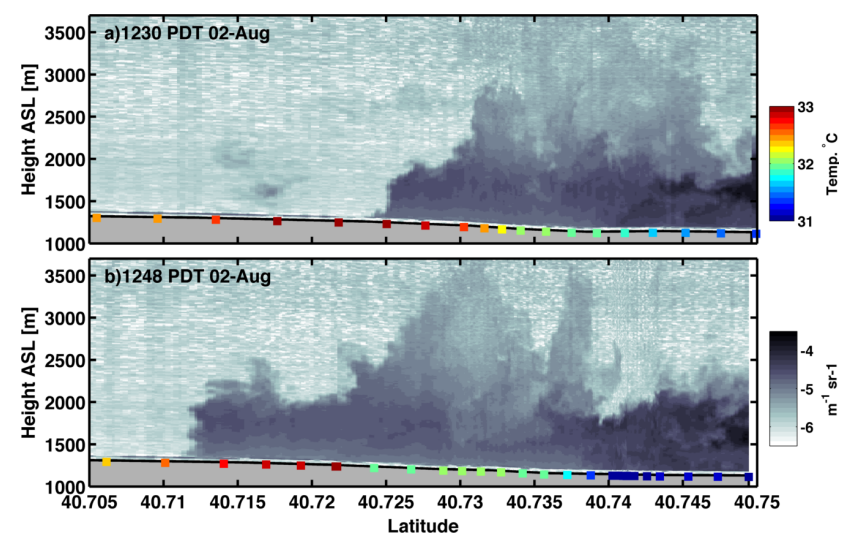

Figure 5. Lidar backscatter $\left(\mathrm{m}^{-1} \mathrm{sr}^{-1}\right)$ during two successive density current intercept on 2 August, 2014 in the Hat Creek valley. The colored squares show the near-surface air temperature.

and propagated across Lake Tahoe. Inspection of the photographs and time-lapse animation (available at: http://youtu. be/SLVKUEoMGwI) indicate the presence of canonical density current features at the leading edge of the smoke layer. The resulting smoke inundation of the Tahoe Basin forced the cancelation of a major sporting event due to hazardous levels of $\mathrm{PM}_{2.5}$ (http://www.ironman.com/triathlon/news/articles/ 2014/09/tahoe-cancellation.aspx\#axzz3RIVH89F0).

Compared to the Bald and Eiler fire cases, the King fire density current is more clearly embedded within a larger scale diurnal wind reversal. Satellite images show a widespread upslope southwesterly flow developing in the early afternoon of 20 September (not shown), which is likely a manifestation of the Washoe Zephyr, a thermally driven wind system that penetrates across the crest the Sierra Nevada and becomes a downslope afternoon wind (Zhong et al., 2008). While this broader wind reversal is important in the displacement of the smoke layer, it is quite clear from the photographic sequence that the local spread characteristics are strongly affected by its density current dynamics. For example the leading edge of the layer advances to the southeast in opposition to the background synoptic-scale flow and exhibits a series of lateral cleft and lobe instabilities.

At issue for future studies is the degree to which diurnal mountain wind systems are altered by smoke shading. Previous investigators have established that smoke can delay, or even prevent, the break up of nocturnal temperature inversions, but no comprehensive studies of smoke-modified thermally driven circulations in complex terrain have been conducted. The smoke-induced density currents examined in this study are likely just one manifestation of these smokeshading effects, and a more comprehensive assessment of smoke-modified boundary layers is needed to better understand local transport of smoke from wildfires.

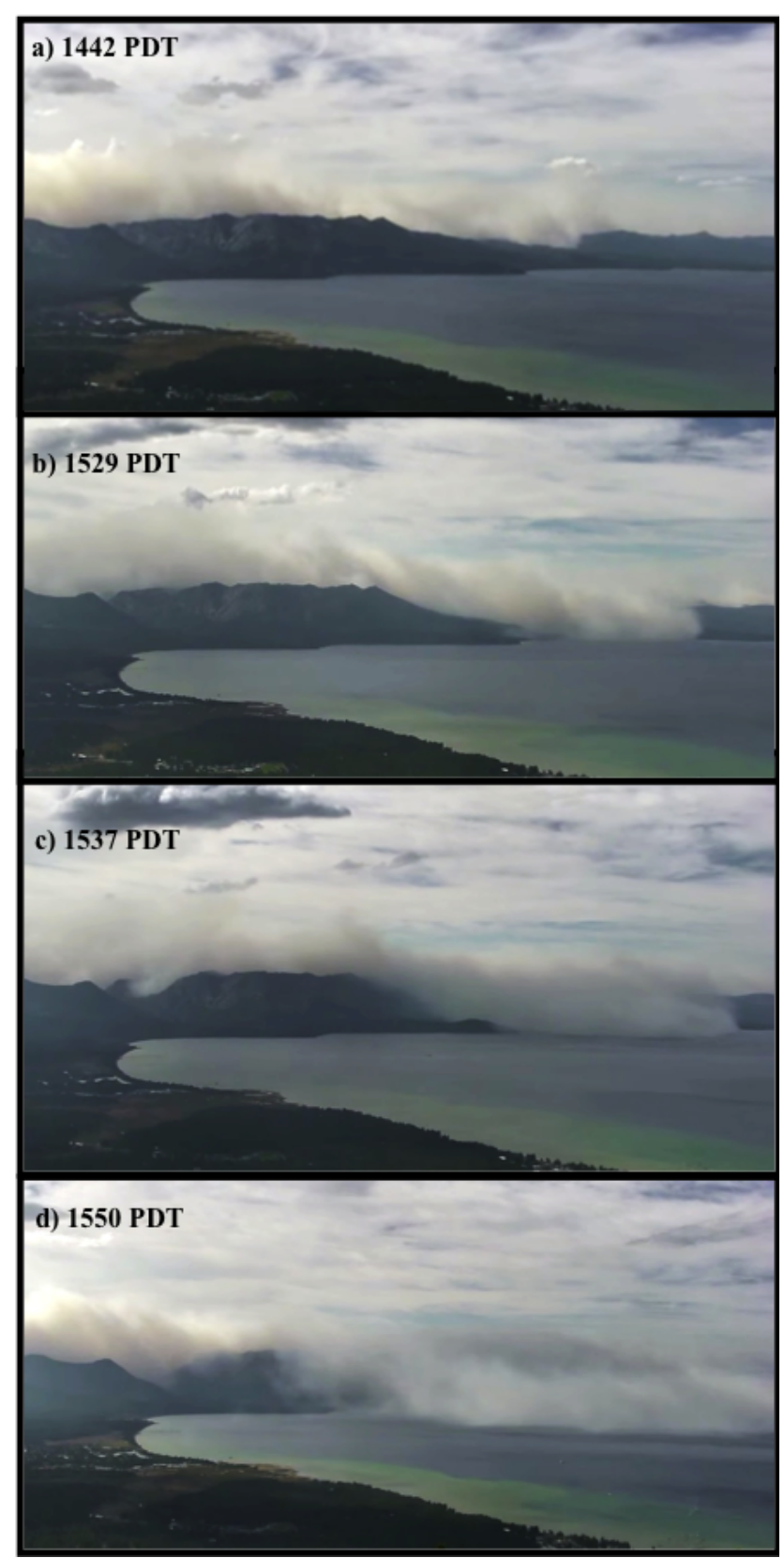

Figure 6. Photographic sequence of a smoke-filled density current originating from the King fire on 20 September 2014. The smoke is observed to spill across the crest of the Sierra Nevada and into the Tahoe Basin. The frames extracted from a time-lapse animation courtesy of the Nevada Seismic Laboratory. Time-lapse available at http://youtu.be/SLVKUEoMGwI.

\section{Conclusions}

In this paper we have presented a set of novel observations of smoke-induced density currents and established that the driving mechanism in their propagation is the thermal difference due to reduced solar insolation beneath the smoke layer. Our results indicate that these self-propagating mesoscale fronts 
can cause severe and unexpected smoke impacts, especially since their flow can oppose the ambient wind. Additional observations indicate that smoke-induced density currents are relatively common near large multi-day wildfires. Our findings also imply that smoke-modified boundary layers might contribute to changes in fire behavior that impact both firefighter and community safety. For example, smoke-induced density currents can contribute to rapid wind shifts, drastic reductions in visibility, and delayed inversion breakup. Since smoke modeling and forecast tools typically neglect smoke radiative forcing they can not account for these phenomena, and due to the inability of satellites to resolve finescale boundary-layer processes there is a need for observational studies within the fire-modified environment to improve our understanding of the broader range of smokemodified boundary layers and other fire-atmosphere interactions and feedbacks.

Author contributions. C. B. Clements conceived the field campaign design, N. P. Lareau and C. B. Clements conducted the measurements and the collection of the data, N. P. Lareau led the data analysis and writing, and C. B. Clements provided contributions to the writing.

Acknowledgements. The lidar, truck, and radiosonde data are available upon request from the authors. The photographs of the smoke-filled density current moving across Lake Tahoe were provided by the Nevada Seismic Laboratory at the University of Nevada, Reno. Satellite data are archived on the The Comprehensive Large Array data Stewardship System (CLASS) at www.class.noaa.gov. This research is supported under grant AGS-1151930 from the National Science Foundation.

Edited by: B. Vogel

\section{References}

Britter, R. E. and Simpson, J. E.: Experiments on the dynamics of a gravity current head, J. Fluid Mech., 88, 223-240, doi:10.1017/S0022112078002074, 1978.

Clements, C. B. and Oliphant, A. J.: The California State University mobile atmospheric profiling system: A facility for research and education in boundary layer meteorology, B. Am. Meteor. Soc., 95, 1713-1724, doi:10.1175/BAMS-D-13-00179.1, 2014.

Delfino, R. J., Brummel, S., Wu, J., Stern, H., Ostro, B., Lipsett, M., Winer, A., Street, D. H., Zhang, L., Tjoa, T., and Gillen, D. L.: The relationship between respiratory and cardiovascular hospital admissions to the southern California wildfires of 2003, Occup. Environ. Med., 66, 189-197, doi:10.1136/oem.2008.041376, 2009

Fromm, M., Lindsey, D. T., Servranckx, R., Yue, G., Trickl, T., Sica, R., Doucet, P., and Godin-Beekmann, S.: The untold story of pyrocumulonimbus, B. Am. Meteor. Soc., 91, 1193-1209, doi:10.1175/2010BAMS3004.1, 2010.
Garrett, J. R., Pittock, A. B., and Walsh, K: Response of the atmospheric boundary layer and soil layer to high altitude, dense aerosol cover, J. Appl. Meteor., 29, 35-52 , doi:10.1175/15200450(1990)029<0035:ROTABL>2.0.CO;2, 1990.

Goodrick, S. L., Achtemeier, G. L., Larkin, N. K., Liu, Y., and Strand, T.: Modeling smoke transport from wildland fires: a review, Int. J. Wildland Fire, 22, 83-94, doi:10.1071/WF11116, 2012.

Hobbs, P. V., Reid, J. S., Kotchenruther, R. A., Ferek, R. J., and Weiss, R.: Direct radiative forcing by smoke from biomass burning, Science, 275, 1176-1178, doi:10.1126/science.275.5307.1777, 1997.

Holstius, D. M., Rei, C. E., Jesdale, B. M., and Morello-Frosch, R.: Birth weight following pregnancy during the 2003 Southern California wildfires, Environ. Health Prespect., 120, 1340-1345, doi:10.1289/ehp.1104515, 2012.

Johnston, F. H., Henderson, S. B., Chen, Y., Randerson, J. T., Marlier, M., Defries, R. S., Kinney, P., Dowman, D. M., and Brauer, M.: Estimated global mortality attributable to smoke from landscape fires, Environ. Health Perspect., 120, 695-701, doi:10.1289/ehp.1104422, 2012.

Johnson, R. H., Young, G. S., Toth, J. J., and Zehr, R. M.: Mesoscale weather effects of variable snow cover over Northeast Colorado, Mon. Weather Rev., 112, 1141-1152, doi:10.1175/15200493(1984)112<1141:MWEOVS>2.0.CO;2, 1984

Lane, S. E., Barlow, J. F., and Wood, C. R.: An assessment of a three-beam Doppler lidar wind profiling method for use in urban areas, J. Wind Eng. Ind. Aerod., 119, 53-59, doi:10.1016/j.jweia.2013.05.010, 2013.

Larkin, N. K., O’Neill, S. M., Solomon, R., Raffuse, S., Strand, T., Sullivan, D. C., Krull, C., Rorig, M., Peterson, J., and Ferguson, S. A.: The BlueSky smoke modeling framework, Int. J. Wildland Fire, 18, 906-920, doi:10.1071/WF07086, 2009.

Mahrer, Y. and Pielke, R. A.: The Effects of Topography on Sea and Land Breezes in a Two-Dimensional Numerical Model, Mon. Weather Rev., 105, 1151-1162, doi:10.1175/15200493(1977)105<1151:TEOTOS>2.0.CO;2, 1977.

Markowski P. and Richardson, Y.: Mesoscale Meteorology in Midlatitudes, John Wiley \& Sons, 430 pp., 2011.

Markowski, P. M., Rasmussen, E. N., Straka, J. M., and Dowell, D. C.: Observations of low-level baroclinity generated by anvil shadows, Mon. Weather Rev., 126, 2942-2958, doi:10.1175/1520-0493(1998)126<2942:OOLLBG>2.0.CO;2, 1997.

Mayor, S. D.: Observations of seven atmospheric density current fronts in Dixon, California, Mon. Weather Rev., 139, 1338-1351, doi:10.1175/2010MWR3374.1, 2011.

Pahlow, M., Kleissl, J., Parlange, M. B., Ondov, J. M., and Harrison, D.: Atmospheric boundary-layer structure observed during a haze event due to forest-fire smoke, Bound.-Lay. Meteorol., 115, 53-70, doi:10.1007/s10546-004-6350-z, 2005.

Penner, J. E., Dickinson, R. E., and O'Neill, C. S.: Effects of aerosol from biomass burning on the global radiation budget, Science, 256, 1432-1434, doi:10.1126/science.256.5062.1432, 1992.

Rife, D. L., Warner, T. T., Chen, F., and Astling , E. G.: Mechanisms for diurnal boundary layer circulations in the Great Basin Desert, Mon. Weather Rev., 130, 921-938, doi:10.1175/15200493(2002)130<0921:MFDBLC>2.0.CO;2, 2002. 
Robock, A.: Enhancement of Surface Cooling Due to Forest Fire Smoke, Science, 242, 911-913, doi:10.1126/science.242.4880.911, 1988.

Robock, A.: Surface cooling due to forest fire smoke, J. Geophys. Res., 96, 2156-2202, doi:10.1029/91JD02043, 1991.

Segal, M. and Arritt, R. W.: Nonclassical mesoscale circulations caused by surface sensible heat-flux gradients, B. Am. Meteor. Soc., 73, 1593-1604, doi:10.1175/15200477(1992)073<1593:NMCCBS>2.0.CO;2, 1992.

Segal, M., Weaver, J., and Purdom, J. F. W.: Some effects of the Yellowstone Fire smoke plume on Northeast Colorado at the end of summer 1988, Mon. Weather Rev., 117, 2278-2284, doi:10.1175/1520-0493(1989)117<2278:SEOTYF>2.0.CO;2, 1989.

Simpson, J. E.: Gravity Currents: In the Environment and the Laboratory, Cambridge University Press, 244 pp., 1997.

Simpson, J. E. and Britter, R. E.: The dynamics of the head of a gravity current advancing over a horizontal surface, J. Fluid Mech., 94, 477-495, doi:10.1017/S0022112079001142, 1979.

Simpson, J. E. and Britter, R. E.: A laboratory model of an atmospheric mesofront, Quart. J. Roy. Meteor. Soc., 106, 485-500, doi:10.1002/qj.49710644907, 1980.
Strand, T. M., Larkin, N., Craig, K. J., Raffuse, S., Sullivan, D., Solomon, R., Rorig, M., Wheeler, N., and Pryden, D.: Analyses of BlueSky Gateway PM2.5 prediction during the 2007 southern and 2008 northern California fires, J. Geophys. Res., 117, D17301, doi:10.1029/2012JD017627, 2012.

Trentmann, J., Luderer, G., Winterrath, T., Fromm, M. D., Servranckx, R., Textor, C., Herzog, M., Graf, H.-F., and Andreae, M. O.: Modeling of biomass smoke injection into the lower stratosphere by a large forest fire (Part I): reference simulation, Atmos. Chem. Phys., 6, 5247-5260, doi:10.5194/acp-65247-2006, 2006.

Wegesser, T. C., Pinkerton, K. E., and Last, J. A.: California wildfires of 2008: Coarse and fine particulate matter toxicity, Environ. Health Perspect., 117, 893-897, doi:10.1289/ehp.0800166, 2009.

Zhong, S., Li, J., Clements. C. B., De Wekker, S. F. J., and Bian, X.: Forcing mechanisms for the Washoe-Zephyr-A daytime downslope wind system in the lee of the Sierra Nevada, J. Appl. Meteor. Climatol., 47, 339-350. doi:10.1175/2007JAMC1576.1, 2008. 